\title{
Origin identification of dried seaweed product "nori" by PCR-RFLP analysis of Pyropia yezoensis in the internal transcribed spacer ITS-1 region
}

\author{
Ken Touhata $\cdot$ Atsushi Namikoshi $\cdot$ Tamami Suzuki $\cdot$ Jun Iguchi $\cdot$ \\ Nanami Mizusawa $\cdot$ Tatsuro Hara $\cdot$ Shintaro Imamura $\cdot$ Takeshi Yabu • \\ Yumiko Yamashita $\cdot$ Michiaki Yamashita
}

Received: 26 April 2013/Accepted: 24 July 2013/Published online: 23 August 2013

(c) The Author(s) 2013. This article is published with open access at Springerlink.com

\begin{abstract}
Nucleotide sequences in internal transcribed spacer (ITS)-1 region derived from dried nori products produced in Japan, China, and the Republic of Korea were compared. Thalli contained in the Japanese products were genetically homogenous, and their nucleotide sequences in ITS-1 were identical to those of the reference strains of Pyropia yezoensis f. narawaensis. In Chinese products, the thalli were related to $P$. yezoensis strain Minomiasakusa. In contrast, the thalli in the Korean products were genetically heterogeneous, and several different $P$. yezoensis strains and other Pyropia spp. were used for dried nori products. In some thalli produced in both China and Korea, the DNA sequences of the ITS-1 region were identical with that of Japan, suggesting that the cultivar strains might have been transplanted from Japan to China in recent years. The 432-bp-long nucleotide sequences in the ITS-1 region of thalli derived from Japanese origin were cleaved to two restriction fragments at 154 and 278 bp by cleavage of PCR-amplified products using MspI. Conversely, almost all of the corresponding sequences derived from China and Korea were lacking $M s p \mathrm{I}$ or other restriction patterns, except for nori products from some areas that cultivate a closely related strain to the Japanese cultivar.
\end{abstract}

K. Touhata $\cdot$ T. Suzuki $\cdot$ N. Mizusawa $\cdot$ T. Hara $\cdot$ S. Imamura T. Yabu $\cdot$ Y. Yamashita $\cdot$ M. Yamashita $(\bowtie)$

National Research Institute of Fisheries Science, 2-12-4

Fukuura, Kanazawa-ku, Yokohama, Kanagawa 236-8648, Japan

e-mail: mic@affrc.go.jp

A. Namikoshi · J. Iguchi

Food and Agricultural Materials Inspection Center,

2-1 Shintoshin, Chuo-ku, Saitama-shi, Saitama 330-9731, Japan
Keywords Dried seaweed - Nori - Pyropia yezoensis · ITS-1 region - RFLP analysis . Origin identification

\section{Introduction}

"Nori" (edible seaweed, Pyropia yezoensis) is one of the most important aquaculture species in Japan [1]. Nori is cultivated on the surface of the sea; the thalli are cut, dried, pressed in a sheet, and then distributed as dried products [1]. Seaweed farms are distributed along the coastal area from southern to northern Japan [1]. Nori is also farmed in China and the Republic of Korea with the help of technological know-how and the transplantation of some strains of P. yezoensis from Japan [1]. P. yezoensis f. narawaensis, which has been established by selective breeding from cultivated populations, now dominates farms in Japan [2, 3].

Labeling is necessary for fresh marine products and processed foods to assist consumers in selecting foods according to the Law on Standardization and Proper Labeling of Agricultural and Forestry Products [Japan Agricultural Standard (JAS) Law]. For imported marine products, country-of-origin food labeling is required in the Japanese market. In addition to the import of nori products from the Republic of Korea, an import quota on nori products from China has been in place since 2005, and dried nori products are now imported from both countries. Therefore, biochemical and genetic techniques for origin identification are needed for dried nori products to certify whether country-of-origin food labeling is correct.

Molecular identification techniques of Pyropia spp. and $P$. yezoensis strains have been developed previously. DNA fingerprinting and PCR-based restriction fragment length polymorphism (RFLP) analysis have been conducted using 
small subunit ribosomal RNA [4], internal transcribed spacer region (ITS) [2, 5-8], plastid ribulose bisphosphate carboxylase/oxygenase gene (RuBisCo) [6-8], and actinrelated protein 4 gene [9]. Park et al. [10] reported genetic polymorphism within wild-collected $P$. yezoensis from Japan and Korea. In 2011, the red algal order Bangiales has been revised based on combined analyses of the nuclear SSU rRNA gene and the RuBisCo L gene [11]. Mitochondrial DNA was also used for the discrimination of 18 Japanese Porphyra and Pyropia species [12]. From these previous studies, Kunimoto et al. [2] and Niwa et al. [8] reported diverse nucleotide sequences in the ITS region among $P$. yezoensis wild-collected and culture strains. Therefore, to develop origin identification techniques for dried nori products, nucleotide sequences in the ITS region are required to determine and compare the thalli DNA extracted from dried nori products produced in Japan, Korea, and China. In Pyropia aquaculture, a mixed culture of several distinct cultivated strains is used for seed production to promote enhanced adaptation to different environmental situations. In addition, natural conchospores may be contaminated by cultivation nets in the sea. Therefore, a possibility existed that distinct DNA sequences derived from several cultured and wild strains might be detected in a single sheet of dried nori product. Thus, we isolated each thallus piece from dried nori products, and carefully determined its nucleotide sequence in the ITS region.

This study focused on differences between the nucleotide sequences in the ITS-1 region from the thalli in dried nori

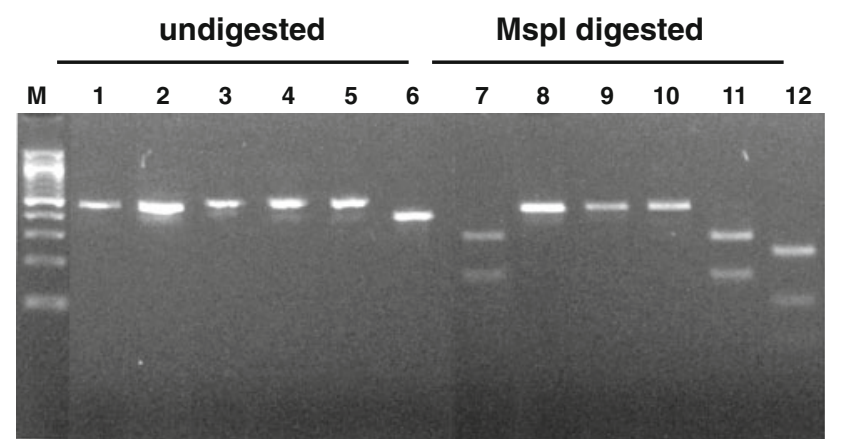

Fig. 1 Comparison of agarose gel electrophoresis patterns for polymerase chain reaction (PCR) products amplified with speciesspecific primers for the DNA sequence of the internal transcribed spacer (ITS)-1 region of Pyropia yezoensis and Pyropia spp. in dried nori products (lanes 1-6) and the subsequent restriction fragment length polymorphism analysis (lanes 7-12). Lane M 100-bp DNA ladder marker; lanes 1 and 7 Pyropia yezoensis Japan_Sub01; lanes 2 and 8 Pyropia yezoensis Japan_Sub02; lanes 3 and 9 Pyropia yezoensis China_Sub01; lanes 4 and 10: Pyropia yezoensis Korea_SubA01; lanes 5 and 11 Pyropia yezoensis Korea_SubB01; lanes 6 and 12 Pyropia sp. NRIFS-1. Note: Pyropia yezoensis Japan_Sub01 (154 and 278 bp), Pyropia yezoensis Korea_SubB01 (152 and $274 \mathrm{bp}$ ), and Pyropia sp. NRIFS-1 (96 and $252 \mathrm{bp}$ ) have two restriction fragments by cleavage of PCR-amplified products by $M s p \mathrm{I}$
Fig. 2 Alignment of nucleotide sequences in the internal transcribed spacer (ITS)-1 region of Pyropia yezoensis thalli in dried nori products produced from Japan, China, and the Republic of Korea. The numbers on the right are the position of the nucleotides. Identical nucleotides to those of Japan_Sub-01 are indicated by dots. Gaps introduced to maximize the alignment are displayed by dashes. The box represents an $M s p I$ site. The partial nucleotide sequence in the ITS-1 region of the Japan_Sub01 genotype identical to that of $P$. yezoensis f. narawaensis [5, 8] is underlined, and used for the phylogenetic analysis in Fig. 3. The nucleotide sequences determined in this study were deposited in the DDBJ/EMBL/GenBank DNA Database (Japan_Sub01: AB818905, Japan_Sub02: AB818906, China_Sub01: AB818907, China_Sub02: AB818908, Korea_SubA01: AB818909, Korea_SubA02: AB818910, Korea_SubA03: AB818911, Korea_SubA04: AB818912, Korea_SubB01: AB818913, Korea_SubB02: AB818914, Korea_SubB03: AB818915)

products produced in Japan, Korea, and China. According to the nucleotide differences between Japanese and the other two countries, we identified marker nucleotide sequences specific to dried nori products produced in Japan, Korea or China. In addition, we developed PCR-RFLP analysis methods for discriminating between the nori products produced in Japan, and those imported from Korea or China.

\section{Materials and methods}

\section{Materials}

Dried nori products were obtained from Japan, China, and Korea between 2006 and 2008. Nori samples were stored with desiccant at $-20{ }^{\circ} \mathrm{C}$ until use.

\section{DNA extraction, PCR amplification, and sequencing}

Nori sheets were cut into small pieces, and individual pieces were swollen and dissociated in distilled water. Each piece of thalli was put into a $1.5-\mathrm{ml}$ tube and then stored at $-20{ }^{\circ} \mathrm{C}$ until use. From 2 to 16 pieces were sampled from each nori sheet. One piece of thallus was thawed and ground with a mortar and pestle. Total DNA was extracted from the ground sample using the Illustra DNA Extraction Kit Phytopure (GE Healthcare, Wauwatosa, WI, USA) or DNeasy Plant Mini Kit (Qiagen, Hilden, Germany) according to the manufacturer's protocol. The nuclear ITS-1 region was amplified using Premix Taq (ExTaq Version: Takara Bio, Ohtsu, Japan) and $0.2 \mu \mathrm{M}$ of the forward primer (CCGTA GGTGAACCTGCGGAAGGATCAT) and the reverse primer (CAAGATATCCACCGCTAAGAGTTGTAT). The PCR program was for $120 \mathrm{~s}$ at $96^{\circ} \mathrm{C}$, followed by $30-40$ cycles of $15 \mathrm{~s}$ at $96{ }^{\circ} \mathrm{C}, 15 \mathrm{~s}$ at $55^{\circ} \mathrm{C}$, and $15 \mathrm{~s}$ at $72{ }^{\circ} \mathrm{C}$, and finally $180 \mathrm{~s}$ at $72{ }^{\circ} \mathrm{C}$. The products were treated with ExoSAP-IT (GE Healthcare) and then sequenced. The plastid RuBisCo and its spacer region were amplified with Premix Taq using $0.2 \mu \mathrm{M}$ of the forward primer 
Japan Sub01

Japan-Sub02

China-Sub01

China-Sub02

Korea-SubA01

Korea-SubA02

Korea-SubA03

Korea-SubA04

Korea-SubB01

Korea-SubB02

Korea_SubB03

Japan Sub01

China-Sub01

China-Sub02

Korea-SubA01

Korea-SubA02

Korea-SubA03

Korea-SubA04

Korea-SubB01

Korea-SubB02

Korea_SubB03

Japan_Sub01

Japan-Sub02

China-Sub01

China-Sub02

Korea-SubA01

Korea-SubA02

Korea-SubA03

Korea- SubA0 4

Korea-SubB01

Korea-SubB02

Korea-SubB03

Japan_Sub01

Japan-Sub02

China-Sub01

China-Sub02

Korea-SubA01

Korea-SubA02

Korea-SubA03

Korea-SubA04

Korea-SubB01

Korea-SubB02

Korea-SubB03

Japan_Sub01

Japan-Sub02

China-Sub01

China-Sub02

Korea-SubA01

Korea-SubA02

Korea-SubA03

Korea-SubA04

Korea-SubB01

Korea-SubB02

Korea-SubB03

Japan_Sub01

Japan-Sub02

China-Sub02

Korea-SubA01

Korea-SubA02

Korea-SubA03

Korea-SubA04

Korea-SubB01

Korea-SubB02

Korea_SubB03

Japan Sub01

Japan-Sub02

China-Sub01

China-Sub02

Korea-SubA01

Korea-SubA02

Korea-SubA03

Korea-SubA04

Korea-SubB01

Korea-SubB02

Korea-SubB03
TCACAAACTATTGACACAAACACACGCGAACCAAATCGTCCGCACAGGTGGTGGCAA-TG $\ldots \ldots \ldots \ldots \ldots \ldots \ldots \ldots \ldots \ldots \ldots \ldots \ldots \ldots \ldots \ldots$

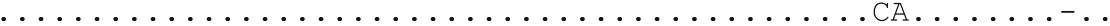
$\ldots \ldots \ldots \ldots \ldots \ldots \ldots \ldots \ldots \ldots \ldots \ldots \ldots \ldots \ldots \ldots \ldots \ldots \ldots \ldots \ldots \ldots$

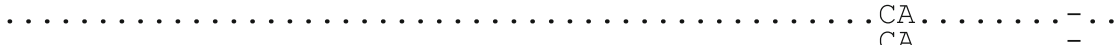

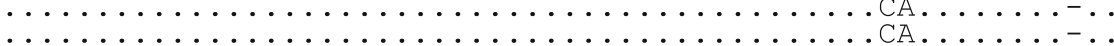
$\cdots \cdots \cdots$

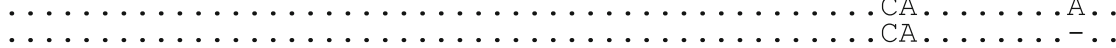

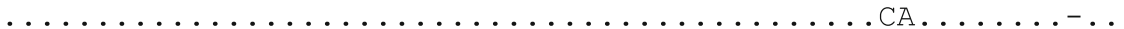

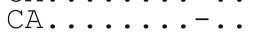

AAAGAGAGAATCTGCATGTCGCCTTTCGGGGTATAGCAAGCAGCACTCTTTTGCCATCGC

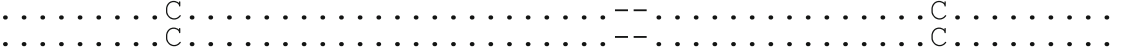

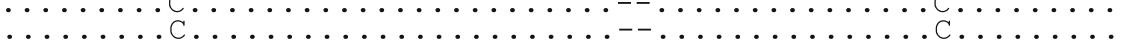
$\cdots \ldots \ldots$

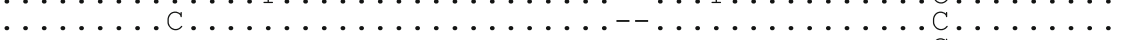

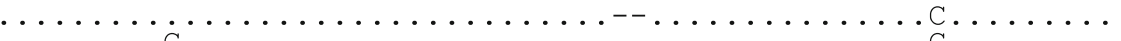

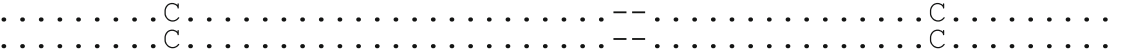

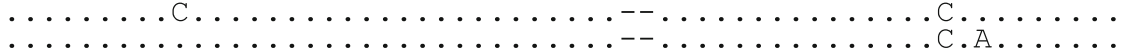
$\ldots \ldots \ldots \ldots \ldots \ldots \ldots \ldots \ldots \ldots \ldots \ldots \ldots \ldots \ldots \ldots \ldots \ldots \ldots \ldots \ldots \ldots \ldots \ldots \ldots \ldots \ldots \ldots$

CTCTGTGCCGGGCGTAAATTCTCATTGAGAGGATGTGAGGGCACCACAGGAAGCTTTTCC

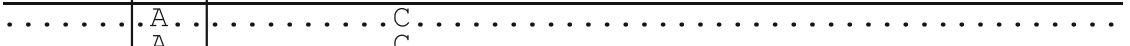

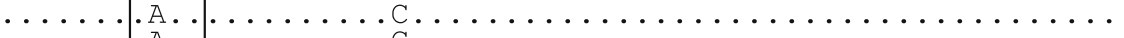

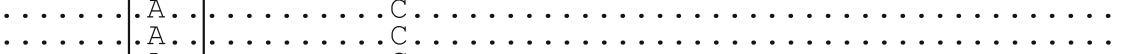

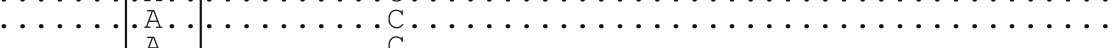

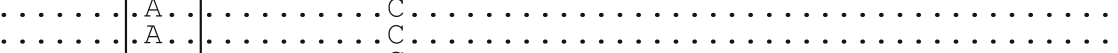

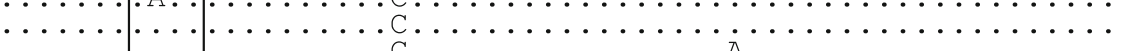

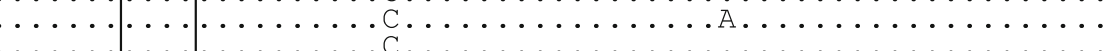

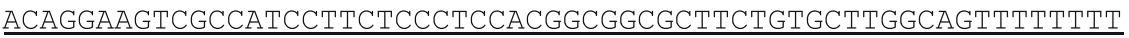


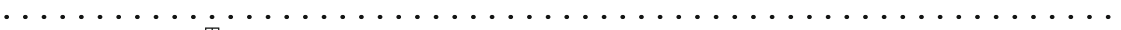

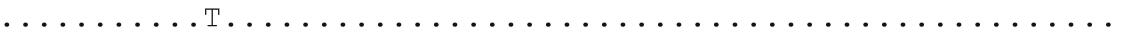

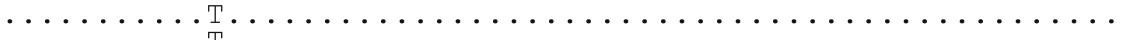
$\ldots$

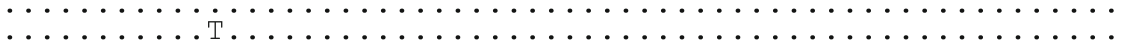

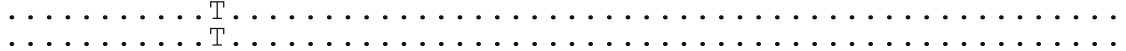

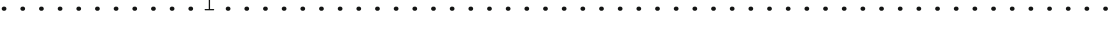
TTTGCCTTCCAGGGAGGATGCCGCCAATGGAGCCCCATATAATATATACATCATCATATG

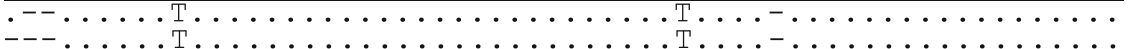

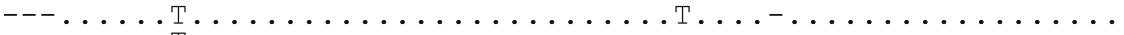

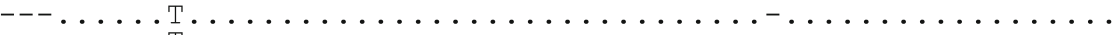

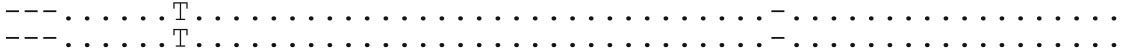

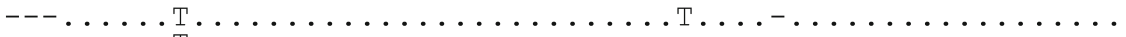

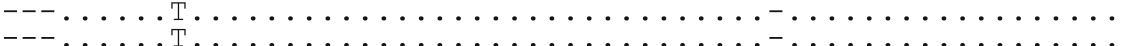

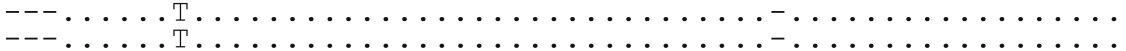
CССстTTTTTCTTAACCGCTTGCCAAAGCTTCTTCTATGAGGAGCTTGTGGGAAGACTG

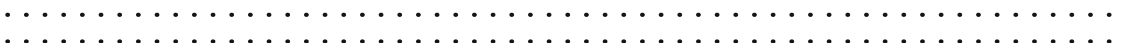

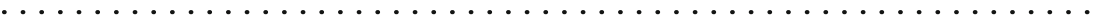

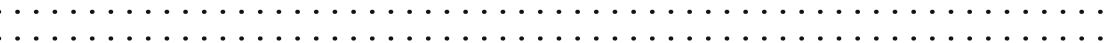

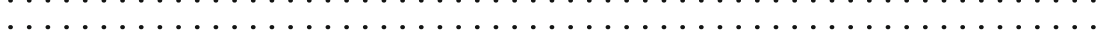

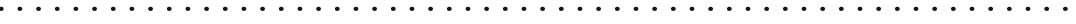
$\cdots \cdots \cdots \cdots \cdots$

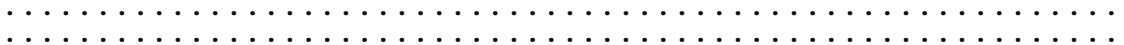

TCTCCATACAATAACAAA-G 378

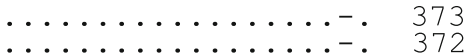

$\ldots \ldots \ldots \ldots \ldots . . \ldots \ldots$

$\ldots \ldots \ldots \ldots \ldots . \ldots \ldots$

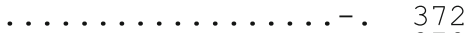

$\ldots \ldots \ldots \ldots . \ldots . \ldots 372$

$\ldots \ldots \ldots \ldots \ldots . \ldots \ldots$

$\ldots \ldots \ldots \ldots \ldots \ldots \ldots \ldots \ldots$

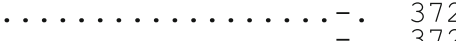

$\ldots \ldots \ldots \ldots \ldots . \ldots . \ldots . \ldots 372$ 


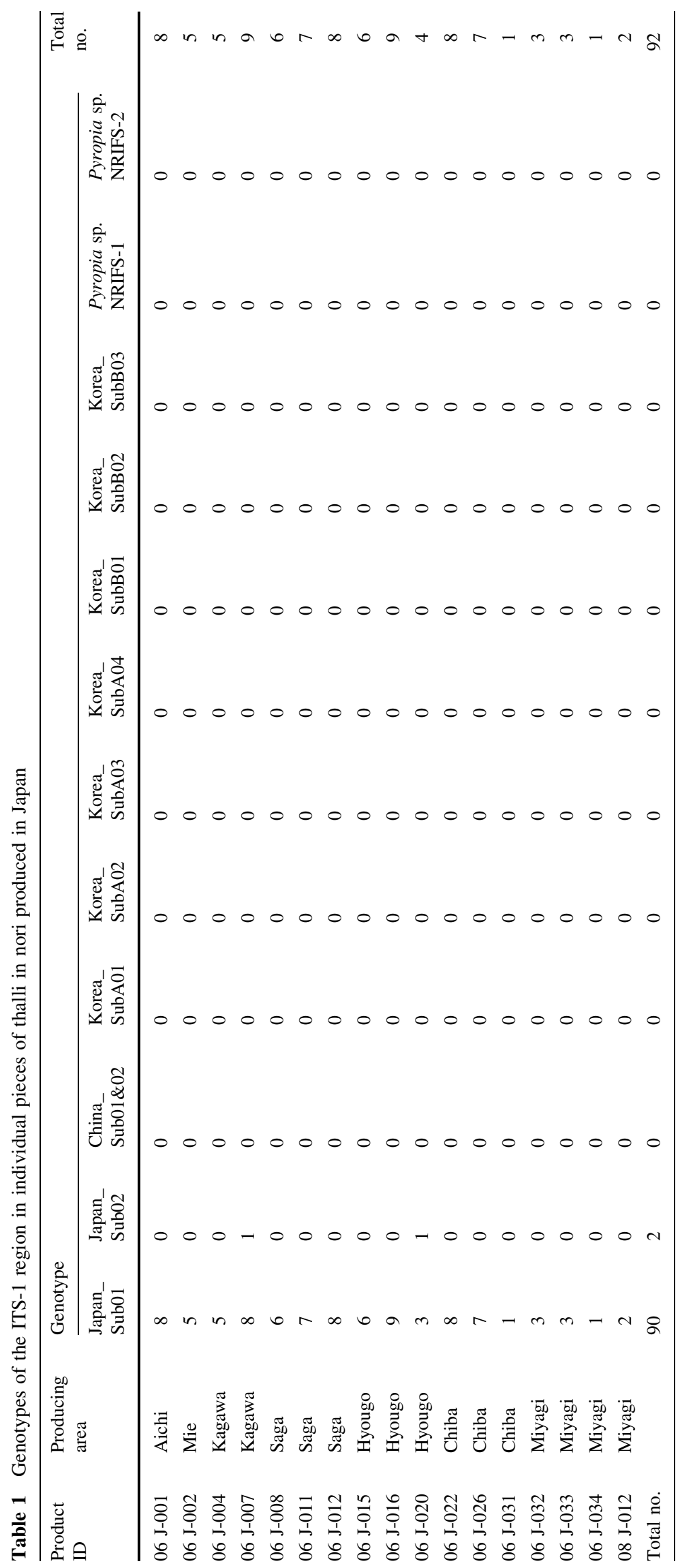




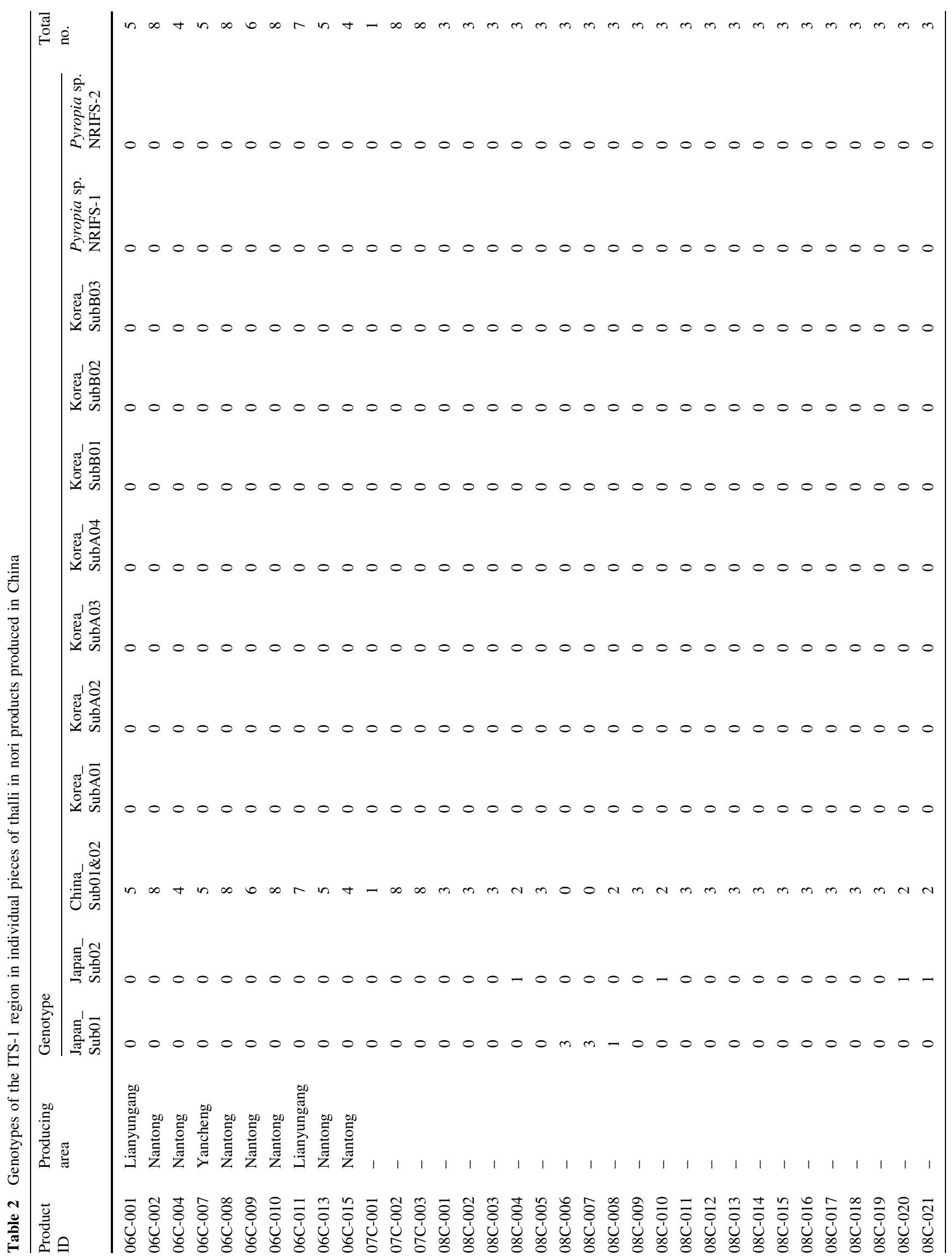




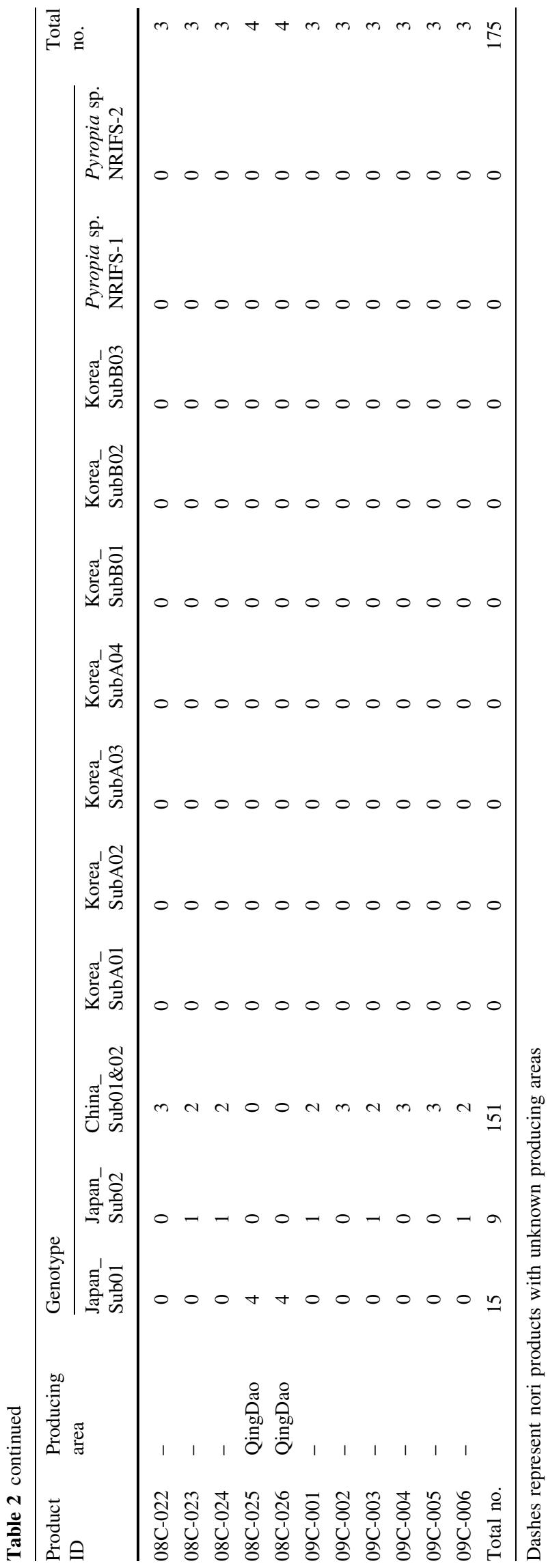

(ATGTCTCAATCCGTAGAATCACG) and the reverse primer (TTAATATCTAGCTCCTTCAGGC) based on the small subunit ribosomal RNA gene and 5.8S ribosomal RNA gene, which are both highly conserved among Pyropia species. The PCR program was for $120 \mathrm{~s}$ at $96^{\circ} \mathrm{C}$, followed by $30-40$ cycles of $15 \mathrm{~s}$ at $96{ }^{\circ} \mathrm{C}, 15 \mathrm{~s}$ at $55^{\circ} \mathrm{C}$, and $60 \mathrm{~s}$ at $72{ }^{\circ} \mathrm{C}$, and finally $180 \mathrm{~s}$ at $72{ }^{\circ} \mathrm{C}$. The products were treated with ExoSAP-IT and then sequenced. The products were sequenced using an ABI PRISM 3100 Genetic Analyzer or ABI PRISM 3130xl Genetic Analyzer (Life Technologies Corporation, Carlsbad, CA, USA) with ABI PRISM BigDye Terminator v3.1. The nucleotide sequences in the ITS-1 region and the RubisCo gene in various Pyropia species were aligned using the CLUSTALW program [13] on the web site of the DNA Database Bank of Japan, and a phylogenetic tree was designed using the Treeview ppc version 1.6.6 program [14]. The nucleotide sequences determined in this study were deposited in the DDBJ/EMBL/GenBank DNA Database (accession numbers AB818905-AB818921).

Restriction fragment length polymorphism

Amplified PCR products of the ITS-1 region were digested with $M s p$ I restriction enzyme (New England Biolabs Japan, Tokyo, Japan). A reaction mixture of $10 \mu \mathrm{l}$ containing from 2 to $3 \mu \mathrm{l}$ of PCR product, 5 units of MspI, $1 \mu \mathrm{l}$ of restriction enzyme buffer, and distilled water was incubated at $37{ }^{\circ} \mathrm{C}$ for at least $3 \mathrm{~h}$. The reaction mixture was separated in a $3 \%$ agarose gel containing ethidium bromide and photographed under ultraviolet light.

\section{Results}

Comparison of nucleotide sequences in the ITS-1 region of the dried nori products

Total DNA was extracted from the dried nori products produced in Japan, China, and Korea, and PCR amplification products were of similar size, approximately $430 \mathrm{bp}$ long, except for some pieces from Korea (Fig. 1, lanes 1-6). The nucleotide sequences of the partial PCR fragment in the approximately 430-bp-long ITS- 1 region were determined to identify DNA polymorphism in Pyropia species and P. yezoensis strains contained in the nori products (Fig. 2).

Almost all of the 343-bp-long partial nucleotide sequences in the ITS- 1 region of 90 pieces of thalli derived from Japanese origin in the present study were identical to those of $P$. yezoensis $\mathrm{f}$. narawaensis. This genotype was tentatively named "Japan_Sub01" in Table 1. In this sequence, we found an MspI gene site at $126 \mathrm{bp}$ as shown in Fig. 2, and two restriction fragments at 154 and 278 bp by 


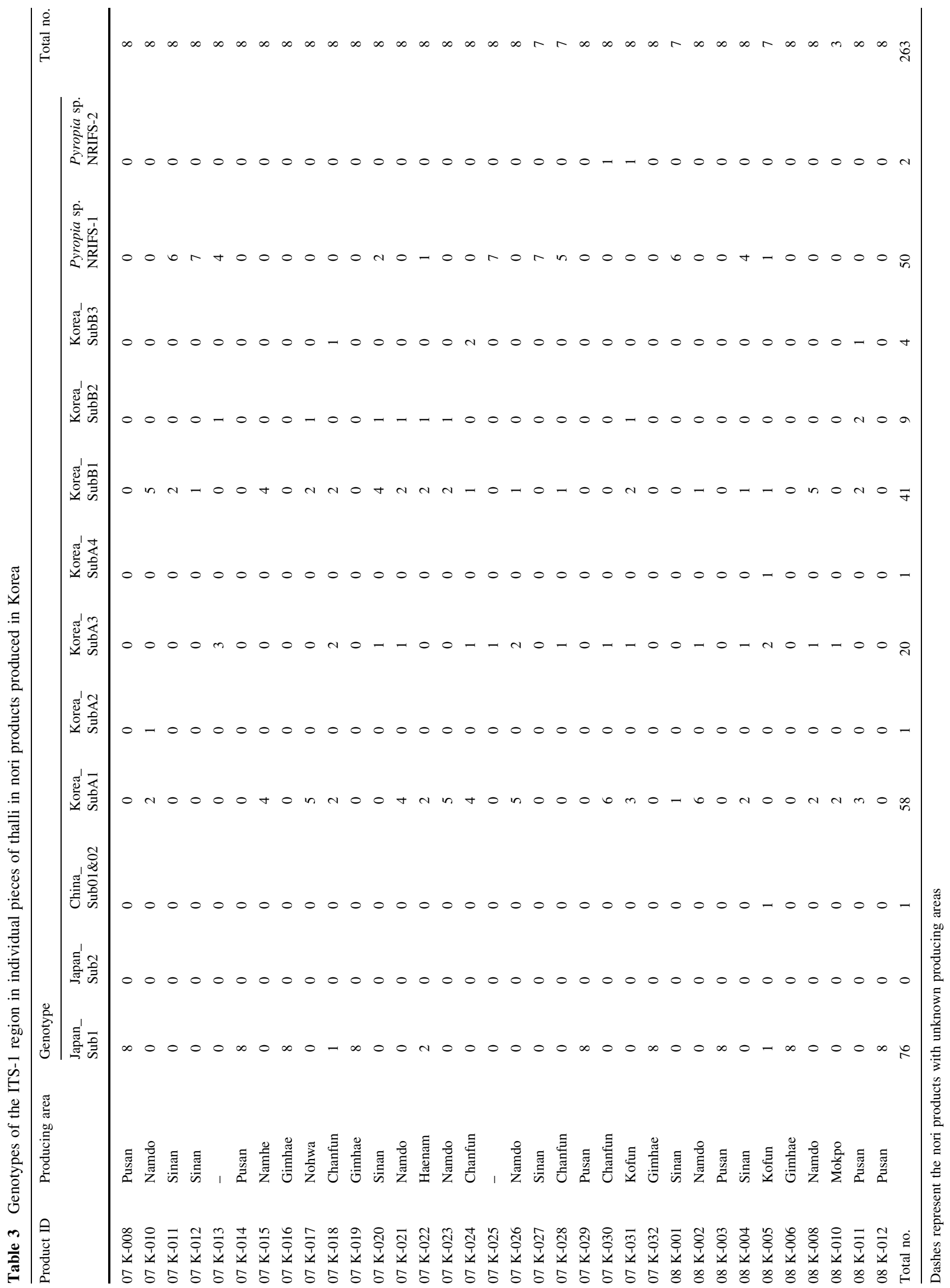


cleavage of PCR-amplified products using MspI restriction enzymes. Therefore, we found close relationships between most of the cultured nori strains, except for two samples that were considered to be a wild strain ("Japan_Sub02"). The Japan_Sub02 genotype was detected in only one piece of thallus, as compared with 15 pieces having the genotype Japan_Sub01.

The dried nori products produced in China had two specific genotypes denoted "China_Sub01" and "China_Sub02" marked by a single nucleotide deletion of the nucleotide sequence of the partial ITS-1 region of the $P$. yezoensis strain Minomiasakusa [2]. The China_Sub02 genotype had a single nucleotide insertion in the region of the 5.8S rRNA gene in the 426-bp long partial ITS-1 sequence in the China_Sub01 genotype. Among 160 pieces of thalli samples prepared from 54 dried nori products in China, 151 pieces had these Chinese-specific genotypes (Table 2). The remaining nine pieces had nucleotide sequences that were identical to Japan_Sub02.

The ITS-1 region was determined in 263 pieces of thalli samples prepared from 34 dried nori products produced in Korea. These 263 nucleotide sequences were classified into

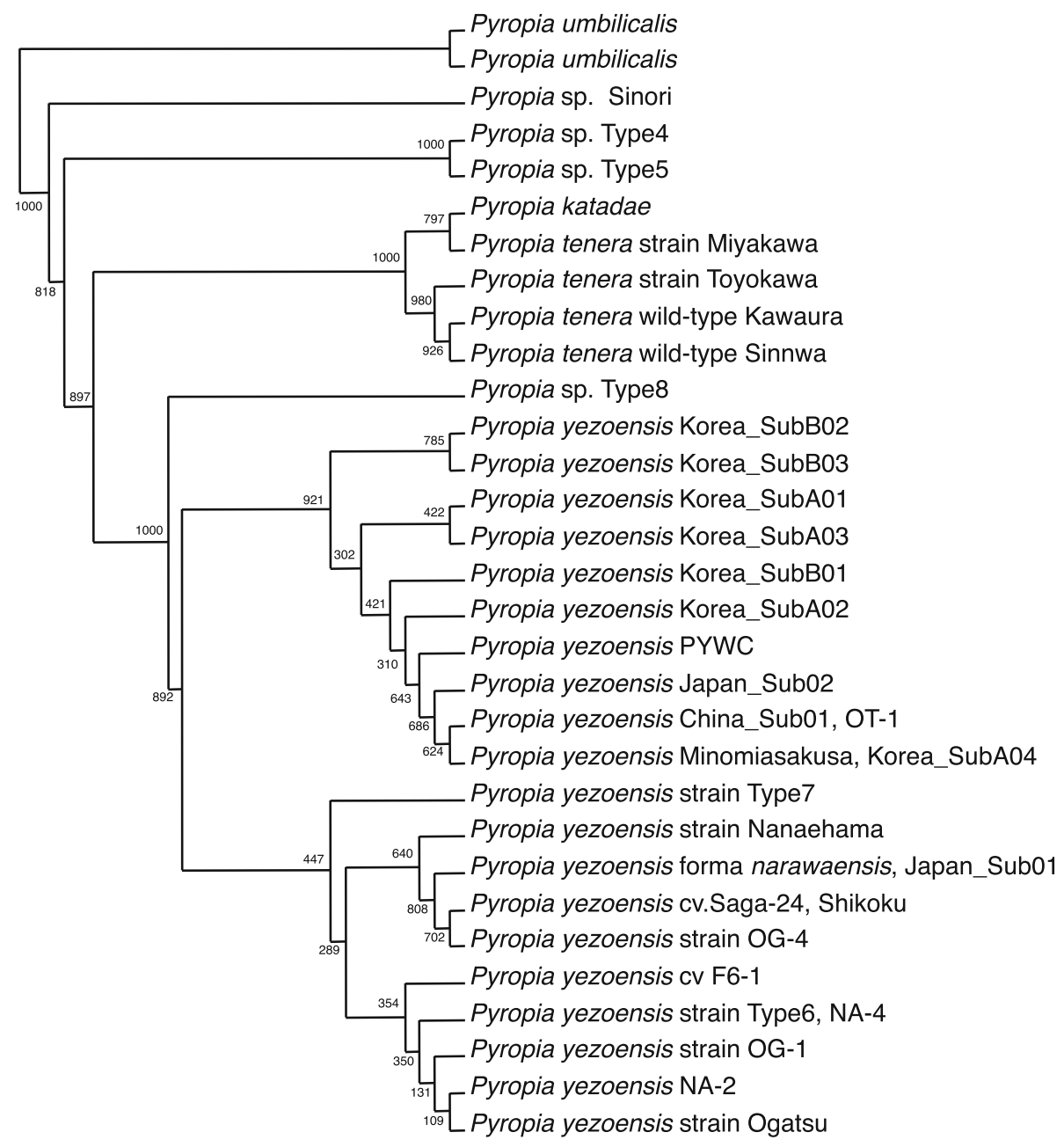

Fig. 3 Phylogenetic tree of the DNA sequence of the 343-bp-long partial ITS-1 region of Pyropia yezoensis and Pyropia tenera strains. Pyropia umbilicalis strains (DDBJ/GenBank/EMBL accession numbers $\mathrm{AB} 017088$ and $\mathrm{AJ} 318959)$ are used as outgroups. The scale indicates the evolutionary distance of the base substitution per site. Bootstrap confidence values for the sequence groupings are indicated in the tree $(n=1,000)$. The nucleotide sequences determined in Japanese dried nori product (Japan_Sub01) and the Pyropia yezoensis cultivar strains (U-51, Saga-5, Sasiki, Oba-green, Fukuoka-,1 D-18-1, Ariake-1, Noma-1, Midorime and Saga103) were identical to the Pyropia yezoensis f. narawaensis reference sequence. Pyropia yezoensis type 6 , type 7 , type 8 , Yunouraasakusa, Ogatsu-4, minohe, and Minomiasakusa are wild types or strains registered by Kunimoto et al. [2]. The DDBJ/GenBank/EMBL accession numbers were as follows: Pyropia sp. Sinori (AB017077), Pyropia katadae (AB017090), Pyropia tenera strain Miyakawa (AB100958), Pyropia tenera strain Toyokawa (AB100959), Pyropia tenera wt Kawaura (AB017073), Pyropia tenera wt Shinwa (AB017072), PYWC (DQ649354), strain OT-1 (AB365994), cv. F6-1(AB017083), strain NA-4 (AB017076), strain OG-2 (AB017079), strain OG-1 (AB017078), strain NA-2 (AB017075), strain Ogatsu (AB243203), cv. Shikoku (AB017087), cv. Saga-24 (AB019192), cv. Midorime (AB017084), strain OG-4 (AB017081) 
11 genotypes of $P$. yezoensis strains: Japan_Sub01, China_Sub01\&02, Korea_SubA01, Korea_SubA02, Korea_SubA03, Korea_SubA04, Korea_SubB01, Korea_ SubB02, Korea_SubB03, and two genotypes of Pyropia sp. NRIFS-1 and NRIFS-2 that were not $P$. yezoensis (Table 3). The genotype Korea_SubA01 was identical to the nucleotide sequences of $P$. yezoensis wild strains NS003 and NS004 isolated from natural seeding on the southwest coast of Korea (accession numbers DQ227869 and DQ227870, respectively). Nucleotide sequences in the ITS-1 region of the genotypes Korea_SubB01, Korea_SubB02, and Korea_SubB03 were identical to those of $P$. yezoensis strains NS005 (accession no. DQ227871), NS002 (accession no. DQ227868), and NS001 (accession no. DQ227867) isolated from the natural seeds of wild strains in Korea, respectively. Thalli whose ITS-1 region's DNA sequences were identical to those in Japan (Japan_Sub01) or China (China_Sub01) were also detected
(Table 3). These genotypes, China_Sub01-02, Korea_SubA01-A04, and Korea_SubB01-B03, closely resembled $P$. yezoensis strain Minomiasakusa, rather than resembling $P$. yezoensis strain f. narawaensis, in phylogenetic analysis (Fig. 3). In addition, two Pyropia spp. whose DNA sequences of the ITS-1 region completely differed from those of $P$. yezoensis strains were detected only in the dried nori products from Korea (Table 3). Among 263 pieces of thalli in the Korean products, 50 pieces contained the 348-bp-long segment of the ITS-1 region (Pyropia sp. NRIFS-1) and two pieces contained the approximately 350-bp-long segment of the ITS-1 region (Pyropia sp. NRIFS-2), whose nucleotide sequences differed from those of $P$. yezoensis. However, we could not determine these nucleotide sequences in the ITS-1 region of Pyropia sp. NRIFS-1 and NRIFS-2 because of highly repetitive nucleotide sequences. We also analyzed the nucleotide sequences of plastid RuBisCo genes.

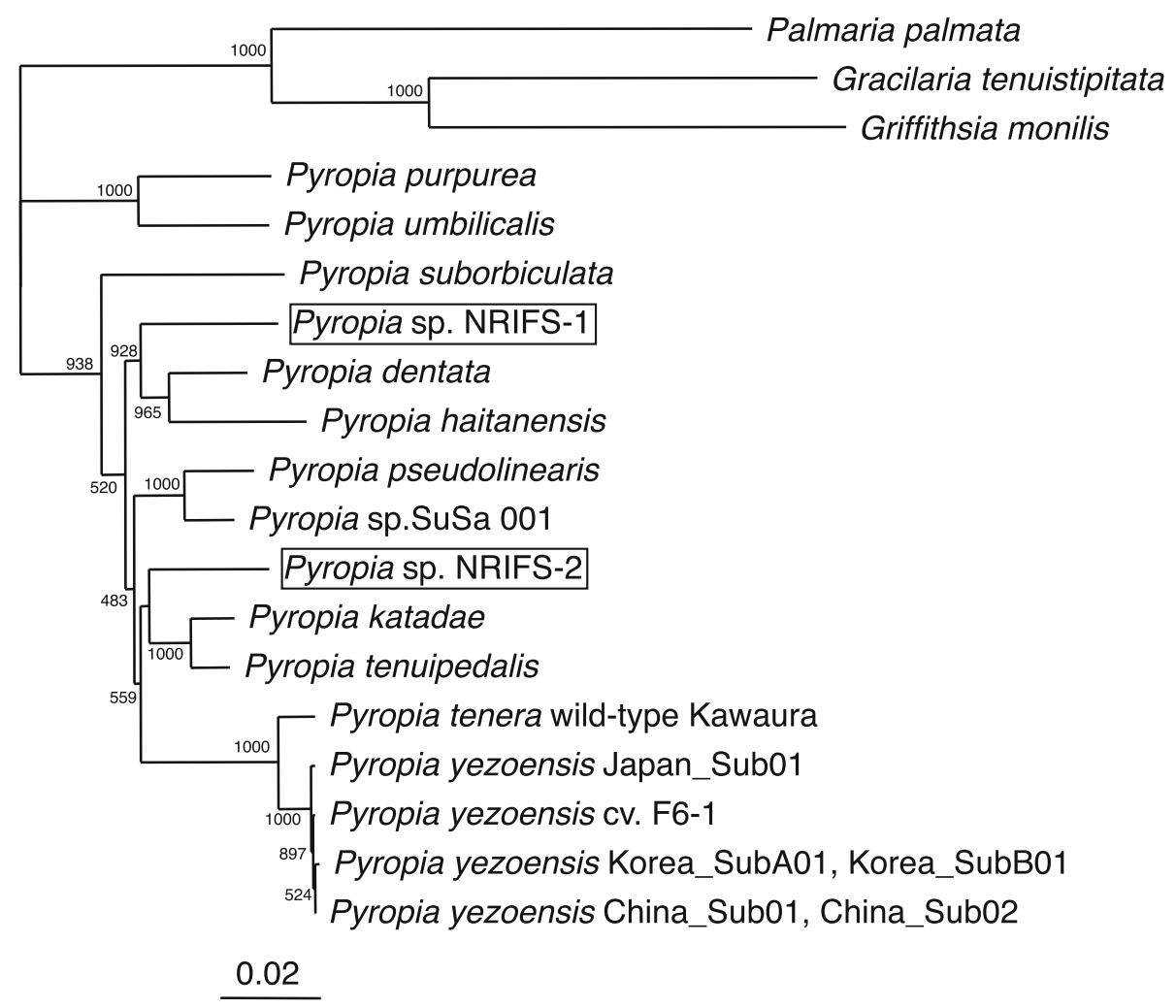

Fig. 4 Phylogenetic tree based on the partial nucleotide sequences of the ribulose bisphosphate carboxylase/oxygenase (RuBisCo) genes in Pyropia species. The scale indicates the evolutionary distance of the base substitution per site. RuBisCo genes of China_Sub01, China_Sub02, Korea_Sub01, and Korea_Sub02 were sequenced from thalli of nori products $07 \mathrm{C}-01,08 \mathrm{C}-24,07 \mathrm{~K}-30$, and $07 \mathrm{~K}-31$, respectively. Palmaria palmata (accession number PPU28421), Griffithsia monilis (accession number EU079379), and Gracilaria tenuistipitata (accession number AY673996) were used as outgroups. Bootstrap confidence values for the sequence groupings are indicated in the tree $(n=1,000)$. Boxes represent the Pyropia sp. NRIFS-1 and NRIFS-2 identified in the present study. The DDBJ/GenBank/EMBL accession numbers were as follows: Pyropia yezoensis Japan_Sub01 (AB818917), China_Sub01/China_Sub02 (AB818918), Korea_Sub01/Korea_Sub02 (AB818919), Pyropia sp. NRIFS-1 (AB81 8920), Pyropia sp. NRIFS-2 (AB818921), Pyropia purpurea (AJ634 465), Pyropia umbilicalis (AB118584), Pyropia suborbiculata (AB118580), Pyropia dentata (AB118579), Pyropia haitanensis (AB118585), Pyropia sp. SuSa 01 (AB118586), Pyropia katadae (AB118583), Pyropia tenuipedalis (AB287951), Pyropia tenera $\mathrm{wt}$ Kawaura (AB118576), and Pyropia yezoensis cv F6-1 (AB118590) 
Phylogenetic analysis based on the nucleotide sequences of the RuBisCo gene in the Pyropia genus showed that these sequences in Pyropia sp. NRIFS-1 and Pyropia sp. NRIFS2 were included in a cluster of Pyropia spp. The nucleotide sequence for Pyropia sp. NRIFS-1 was closely related to those of $P$. dentata and $P$. haitanensis (Fig. 4), and identical by 95 and $94 \%$, respectively. The nucleotide sequence of Pyropia sp. NRIFS-2 was closely related to P. katadae and P. tenuipedalis (Fig. 4), and was identical by 96 and $96 \%$, respectively. By additional BLAST analyses using the RuBisCo L gene, the nucleotide sequence of Pyropia sp. NRIFS-1 was very similar to that of $P$. seriata that was isolated in Kumamoto, Japan (HQ687533) [11] with $99.8 \%$ nucleotide identity. The nucleotide sequence of Pyropia sp. NRIFS-2 in the RuBisCo L gene was identical to those of $P$. kuniedae (HQ728200) and P. pulchella (GU046419) [11].

In contrast, nine dried nori products produced in Gimhae and Pusan (Table 3) contained only the thalli of the strain whose DNA sequence was identical with that from Japan (Japan_Sub01).

\section{RFLP analysis}

The nucleotide sequences showed two distinct RFLP patterns using MspI that differed by origin. The genotype Japan_Sub01 contained a 432-bp-long DNA sequence with an MspI site, resulting in 154 and 278-bp fragments isolated by RFLP (Fig. 1, lane 7). Other genotypes such as Japan_Sub02, China_Sub01, Korea_SubA01, Korea_SubA02, and Korea_SubA03, found in most of the dried nori products produced in China and Korea, contained a DNA sequence with no MspI site (Fig. 1, lanes 8-10). Other genotypes, such as Korea_SubB01, Korea_SubB02, and Korea_SubB03, also contained a 426-bplong DNA sequence with an MspI site (Fig. 1, lane 11). In 116 dried nori products from Japan, PCR products with no $M s p$ I site were detected in only two pieces of thalli from over 1,200 samples.

\section{Discussion}

The nucleotide sequences of the ITS region extracted from the thalli of dried nori products from Japan, China, and Korea were compared to discriminate between countries-oforigin for the food labeling of dried nori products. Differences in the nucleotide sequences of dried nori products from Japan, China, and Korea were identified, and genetic variation in $P$. yezoensis and other related species was characterized in these different country-of-origin products.

In Japanese products, the genetic variation of $P$. yezoensis was very low, and the nucleotide sequences in the ITS region of almost all products were identical to the genotype Japan_Sub01, which corresponded to the reference strains of $P$. yezoensis f. narawaensis (i.e., U-51, Saga-5, Sasiki, Fukuoka-1, Ariake-1, and Saga103) [5, 8]. The two exceptional cases in which we detected the genotype Japan_Sub02 may have been due to contamination by wild strains in the aquaculture field. In recent years, specific strains have been obtained by the selective breeding of $P$. yezoensis f. narawaensis in Japanese institutes and have been applied in commercial production [1-3]. Therefore, genetic homogeneity may be increased by the selective breeding of nori cultivar strains. In Chinese products, the cultivar strain that was closely related to the $P$. yezoensis strain Minomiasakusa, was detected in 41 of the 45 products used in this study. The Minomiasakusa strain was established from a wild strain in 1979 by a Japanese company (http://www.hinsyu.maff.go.jp/tokei/contents/14_ 2012kaiso.pdf). The genotypes China_Sub01 and China_Sub02 may have been derived from the Minomiasakusa strain and transplanted from Japan. On the other hand, three products produced in Qingdao had the genotype Japan_Sub01 identical to that of $P$. yezoensis f. narawaensis, suggesting that cultivar strains may have been transplanted from Japan to China in recent years.

In the Korean products, many genetically distinct genotypes of strains were detected. Four genotypes, Korea_SubA01,SubB01,SubB02, and SubB03, were identical to known cultivar strains of $P$. yezoensis isolated from natural seeds of Korea's southwest coast, according to the DNA database. These genotypes have never been found in Japanese products or cultivar and wild strains, suggesting they were transplanted from Japan in earlier years. Based on the partial nucleotide sequences in the RuBisCo L gene, the sequence of Pyropia sp. NRIFS-1 was closely related to that of P. seriata [11], and that of Pyropia sp. NRIFS-2 was identical to those of $P$. kuniedae and P. pulchella [11]. These were used in the Korean products, indicating that Pyropia species, other than $P$. yezoensis, are also cultured for the production of dried nori products. In addition, the genotype Japan_Sub01 of P. yezoensis was also used in the Korean products, suggesting that this genotype was transplanted from Japan in recent years. Recent studies characterized the phylogenetic relationship in Pyropia spp. by analyses of mitochondrial and plastid DNA [11, 12]. Therefore, mitochondrial and plastid DNA analysis may also be useful for species and origin identification of the Korean dried nori products.

This study showed that RFLP analysis of the ITS region by cleavage with $M s p I$ is useful for the discrimination of Japanese domestic dried nori products versus those imported from China and Korea. However, some exceptional samples from the Chinese or Korean products showed similar RFLP patterns to Japanese products. In 
such cases, multiple trace elemental analysis can support RFLP analysis by MspI cleavage [15].

Acknowledgments The authors are grateful to Dr. Masahiko Kunimoto for helpful suggestions. We thank the Japan Fisheries Cooperatives, Japan Nori Association, National Federation of Nori and Clams Fisheries Cooperatives, Okayama Prefectural Fisheries Experiment Station, Saga Prefectural Ariake Fisheries Research and Development Center, Seikai National Fisheries Institute, Takaokaya Inc., and Fujimori-Shoten for providing the seaweed samples. This work was supported by funding from the Fisheries Agency, Japan.

Open Access This article is distributed under the terms of the Creative Commons Attribution License which permits any use, distribution, and reproduction in any medium, provided the original author(s) and the source are credited.

\section{References}

1. Chen J, Xu P (2005) Porphyra spp. cultured aquatic species information programme. http://www.fao.org/fishery/culturedspecies/ Porphyra_spp/en

2. Kunimoto M, Kito H, Kaminishi Y, Mizukami Y, Murase N (1999) Molecular divergence of the SSU rRNA gene and internal transcribed spacer 1 in Porphyra yezoensis (Rhodophyta). J Appl Phycol 11:211-216

3. Miura A (1984) A new variety and a new form of Porphyra (Bangiales, Rhodophyta) from Japan: Porhyra tenera Kjellman var. tamatsuensis Miura, var. nov. and $P$. yezoensis Ueda form narawaensis Miura, form nov. J Tokyo Univ Fish 1984:1-14

4. Mizukami Y, Kaminishi Y, Kunimoto M, Kobayashi M, Murase N, Kito H (1998) Comparison of partial nucleotide sequences in the exonic region of a small subunit ribosomal RNA gene for discrimination of laver (Porphyra) species and cultivars. Fish Sci 64:886-891

5. Mizukami Y, Kito H, Kaminishi Y, Murase N, Kunimoto M (1999) Nucleotide sequence variation in the ribosomal internal transcribed spacer regions of cultivated (cultivars) and field-collected thalli of Porphyra yezoensis. Fish Sci 65:788-789
6. Niwa K, Aruga Y (2006) Identification of currently cultivated Porphyra species by PCR-RFLP analysis. Fish Sci 72:143-148

7. Niwa $K$, Iida S, Kato A, Kawai H, Kikuchi N, Kobiyama A, Aruga Y (2009) Genetic diversity and introgression in two cultivated species (Porphyra yezoensis and Porphyra tenera) and closely related wild species of Porphyra (Bangiales, Rhodophyta). J Phycol 45:493-502

8. Niwa K, Kato A, Kobiyama A, Kawai H, Aruga Y (2008) Comparative study of wild and cultivated Porphyra yezoensis (Bangiales, Rhodophyta) based on molecular and morphological data. J Appl Phycol 20:261-270

9. Park E-J, Endo H, Kitade Y, Saga N (2008) Simple differentiation of two closely related species Porphyra tenera and Porphyra yezoensis (Bangiophyceae, Rhodophyta) based on length polymorphism of actin-related protein 4 gene (ARP4). Fish Sci 74:613-620

10. Park EJ, Fukuda S, Endo H, Kitade Y, Saga N (2007) Genetic polymorphism within Porphyra yezoensis (Bangiales, Rhodophyta) and related species from Japan and Korea detected by cleaved amplified polymorphic sequence analysis. Eur J Phycol 42:29-40

11. Sutherland JE, Lindstrom SC, Nelson WA, Brodie J, Lynch MDJ, Hwang MS, Choi H-G, Miyata M, Kikuchi N, Oliveira MC, Farr T, Neefus C, Mols-Mortensen A, Milstein D, Müller KM (2011) A new look at an ancient order: generic revision of the Bangiales (Rhodophyta). J Phycol 47:1131-1151

12. Abe M, Kobayashi M, Fujiyoshi E, Tamaki M, Kikuchi N, Murase N (2013) Use of PCR-RFLP for the discrimination of Japanese Porphyra and Pyropia species (Bangiales, Rhodophyta). J Appl Phycol 25:225-232

13. Thompson JD, Higgins DG, Gibson TJ (1994) CLUSTAL W: improving the sensitivity of progressive multiple sequence alignment through sequence weighting, position-specific gap penalties and weight matrix choice. Nucl Acids Res 22:4673-4680

14. Page RDM (1996) TreeView: an application to display phylogenetic trees on personal computers. Comp Appl Biosci 12:357-358

15. Yamashita M, Namikoshi A, Iguchi J, Takashima Y, Hossain MA, Yabu T, Yamashita Y (2008) Molecular identification of species and the geographic origin of seafood. In: Tsukamoto $\mathrm{K}$ et al (eds) Fisheries for global welfare and environment. Terrapub, Tokyo, pp 297-306 